\title{
Natural occurrence of the entomopathogenic fungi Beauveria bassiana as a vertically transmitted endophyte of Pinus radiata and its effect on above- and below-ground insect pests
}

\author{
M.-C. Lefort ${ }^{1,2}$, A.C. McKinnon ${ }^{1}$, T.L. Nelson ${ }^{1}$ and T.R. Glare ${ }^{1}$ \\ ${ }^{1}$ Bio-Protection Research Centre, PO Box 85084, Lincoln University, Lincoln 7647, Christchurch, \\ New Zealand \\ ${ }^{2}$ Department of Natural Sciences, Unitec Institute of Technology, Auckland, New Zealand \\ Corresponding author: Marie-Caroline.Lefort@lincolnuni.ac.nz,mlefort@unitec.ac.nz
}

\begin{abstract}
The New Zealand forest industry would greatly benefit from a successful way of controlling insect pests. The entomopathogenic fungus, Beauveria bassiana, could hold such potential. It has previously been shown to be capable of endophytic colonisation of the Monterey pine Pinus radiata. We investigated B. bassiana transmission in P. radiata and whether this fungus, while acting as an endophyte, was beneficial to this tree species by testing its effect on above- and below-ground insect feeders. Beauveria bassiana was detected in $P$. radiata seedlings which had not previously been exposed to the fungus, indicating a vertical mode of transmission. The presence of the fungus negatively affected the fitness of below-ground insects feeding on the plant by reducing their survival by over $10 \%$ and their weight by about $5 \%$. This vertically-transmitted beneficial endophyte of pine could be used cost-effectively to control insect pests in commercially-grown $P$. radiata plantations.
\end{abstract}

Keywords Biological control, Helicoverpa armigera, Costelytra zealandica, Pinus radiata, Beauveria bassiana

\section{INTRODUCTION}

Pinus radiata D. Don (Pinales: Pinaceae) is a fast-growing softwood intensively used in the forest industry around the world (Mead 2013). This species is the most extensively planted commercially-produced tree in New Zealand (New Zealand Ministry of Primary Industry 2014). The cost-effective management of forests requires both biological and socio-economic factors (Mead 2013) to be considered in order to maximise the return on investment. Pinus radiata is highly susceptible to a range of damaging insect species, comprising both above- and below-ground feeders. The common terrestrial insect pathogenic fungi Beauveria spp. Vuillemin (Ascomycota: Hypocreales), occurs on multiple hosts in most regions of the world (Bissett \& Widden 1988; Rehner et al. 2011), and could be used in a cost-effective way to control insect pests in commercially-grown trees. Beauveria bassiana (Bals.) Vuill., has been reported to be endophytic in a variety of plant species (Vidal 
\& Jaber 2015), including in $P$. radiata (Reay et al. 2010; Brownbridge et al. 2012). There is some evidence that while acting as a plant endophyte, Beauveria can reduce pest damage (Gurulingappa et al. 2010; Akello and Sikora 2012; Castillo Lopez et al. 2014) by inhibiting insect development and reproduction and may also be antagonistic to plant pathogens (Ownley et al. 2008; Ownley et al. 2010).

Although much of the literature reports endophytic establishment of B. bassiana following artificial inoculation, natural occurrence in $P$. radiata seed, needles and roots was reported for $15 \%$ of trees tested (Reay et al. 2010), supporting the possibility that the fungus could be vertically transmitted. (Quesada Moraga et al. 2014). The role of endophytic $B$. bassiana as an active and protective agent in $P$. radiata has not been demonstrated (Brownbridge et al. 2012). The present study aimed to evaluate the prevalence of endophytic $B$. bassiana in the Monterey Pine $P$. radiata sourced from forestry seed lines, and to test whether the occurrence of the fungi reduces the fitness of above- and below-ground insect pests. The invasive corn earworm Helicoverpa armigera (Hübner) (Lepidoptera: Noctuidae) and larvae of the New Zealand beetle Costelytra zealandica (White) (Coleoptera: Scarabaeidae), two phytophagous pests reported to cause significant damage to $P$. radiata pines (Chapman 1984; Herman \& Davidson 2000), were chosen as models of above- and below-ground insect feeders respectively for this study.

\section{MATERIALS AND METHODS \\ Investigation of Beauveria bassiana transmission in Pinus radiata}

Detection of Beauveria bassiana in emergent seedlings

This study used $P$. radiata seedlings grown from commercial seeds (PF Olsen seed, GF Plus; Amberley \& Kaingaroa and Seddon, NZ). To determine if Beauveria was present in the seed, thirty seeds were surface sterilised (1 min 70\% EtOH, 7 min $0.04 \% \mathrm{NaClO}$, washed $2 \times 1 \mathrm{~min}$ sterile distilled $\left.\mathrm{H}_{2} \mathrm{O}\left(\mathrm{sdH}_{2} \mathrm{O}\right)\right)$, and grown on
$1 \%$ water agar media in sterile conditions for approximately 10 days at $22^{\circ} \mathrm{C}$. Seedlings were cut into $2 \mathrm{~cm}$ sections and placed on Beauveria semi-selective media (BSM) plates and incubated for 21 days at $20^{\circ} \mathrm{C}$ in the dark (Brownbridge et al. 2012). A further twenty seeds were germinated and subsequently whole seedlings were surface sterilised following the same procedure, then cut transversally with one half of the radicle stored at $4^{\circ} \mathrm{C}$ for microscopic analysis. The rest of the radicle was processed to obtain DNA for Beauveria endophyte detection by PCR.

Identification of Beauveria cultured from seedlings Samples from fungal cultures obtained from surface sterilised plant sections were grown 24-48 hours in PDB (Difco) at $\sim 22^{\circ} \mathrm{C}$ at $160 \mathrm{rpm}$. Hyphae were ground using liquid nitrogen, and DNA was extracted using a Plant Genomic DNA Extraction System (Viogene, Taiwan) following the manufacturer's protocol and re-suspended in 200 $\mu \mathrm{l}$ of water. DNA from pure fungi was amplified for a fragment of TEF1- $\alpha$ gene using the primers EF349 (5'- TGGCCACCAGCACTCACTAC) and EF1685R (5'-ATGTCACGGACGGCGAAA) (Reay et al. 2010). PCR products were sequenced to confirm identity and checked for identification using BLASTn (Altschul et al. 1990), then aligned with sequences obtained from previously published phylogenies (Rehner et al. 2011) to confirm species identification.

\section{PCR detection of Beauveria in planta}

Primers designed to amplify a $431 \mathrm{bp}$ fragment of EF-1 $\alpha$ were optimised specifically for direct detection of endophytic Beauveria sp. from all $P$. radiata DNA samples in a one-step PCR experiment (primer sequences as follows EF52F 5'-3': TGACAAGCTCAAGGCCGAG and EF481R 5'-3': GGAGGGCTCAAGCATGTTGT). Amplifications were carried out in a thermal cycler using 40 cycles of $45 \mathrm{sec}$ at $95^{\circ} \mathrm{C}, 45 \mathrm{sec}$ at $60^{\circ} \mathrm{C}$ and $90 \mathrm{sec}$ at $72^{\circ} \mathrm{C}$. Pure $P$. radiata DNA previously obtained (McKinnon, 2011) was also included in each run as a plant DNA positive control to 
ensure specificity of the reaction. PCR products were sequenced and checked for identification using BLASTn and aligned with TEF-1a sequences obtained from the Genbank (NCBI) database and local (unpublished) sequence data to conduct a phylogenetic analysis. Nucleotide alignments were performed in Genious Pro ver. 5.6.5. (Biomatters Ltd, NZ) using the Clustal W. algorithm with default parameters and phylogenetic analysis was conducted in MEGA version 6 (Tamura et al. 2013). The evolutionary distances were computed in MEGA using the Maximum Composite Likelihood method (Tamura et al. 2011) and were in the units of the number of base substitutions per site. The final analysis involved 15 nucleotide sequences. All positions containing gaps and missing data were excluded. There were a total of 260 positions in the final dataset.

All pine DNA samples were simultaneously amplified with the universal plant primers psbA3_f (Sang et al. 1997) and trnHf_05 (Tate \& Simpson 2003) to confirm that DNA was present and the PCR effective.

The sensitivity of the PCR detection assay was tested against a serial dilution of $B$. bassiana DNA spiked into pure plant DNA and $\mathrm{sdH}_{2} \mathrm{O}$. The DNA concentration was ascertained using a Qubit $^{\oplus}$ Fluorometer and the number of genome/ TEF1-a gene copies calculated per microliter of sample. Using this dilution series as gDNA template, the EF52F and EF481R primers were able to amplify as little as 3 copies of the Beauveria TEF- $1 \alpha$ gene (equivalent to $3 \mathrm{CFU} / \mu$ l water), with bands visualised on $1.2 \%$ agarose gel in TAE.

\section{Visualisation of endophytic fungi with transmission} electron microscopy

To visualise the fungus in the seedlings, stored pine samples were prepared for preliminary light microscopic analysis as described above. The direct PCR detection method determined that only one of the twenty seedlings was positive for B. bassiana. Light microscopy on fixed and sectioned material confirmed that 19 other pine samples contained no obvious fungal endophytes. The single positive seedling sample was fixed for TEM by immersion for 2 hours at room temperature (RT) in $2 \%$ glutaraldehyde $/ 3 \%$ formaldehyde in $0.1 \mathrm{M}$ phosphate buffer ( $\mathrm{pH} 7.2$ ), followed by 3 washes in $0.1 \mathrm{M}$ phosphate buffer ( $\mathrm{pH} 7.2$ ) and then stored in $1 \%$ formaldehyde in $0.1 \mathrm{M}$ phosphate buffer $\mathrm{pH}$ 7.2 at $4^{\circ} \mathrm{C}$. Samples were processed in $1 \%$ osmium tetroxide in $0.05 \mathrm{M}$ phosphate buffer ( $\mathrm{pH} 7.2)$ at RT for 1,2 and $4 \mathrm{~h}$, then washed three times in $0.05 \mathrm{M}$ phosphate buffer. Dehydration was through an acetone series at RT, then embedded in an epoxy resin (Procure 812, ProSciTech Pty, Australia) at $60^{\circ} \mathrm{C}$ for $22 \mathrm{~h}$. Sections were stained with uranyl acetate followed by lead citrate and examined with a Morgagni 268D TEM (FEI Company, Oregon, USA) operating at $80 \mathrm{kV}$ and fitted with a $40 \mu \mathrm{m}$ objective aperture. Images were captured digitally.

\section{Effect of endophytic Beauveria bassiana on insects in Pinus radiata \\ Model system}

Third instar larvae of the New Zealand grass grub, Costelytra zealandica, were collected from a dairy pasture recently converted from a pine forest in the North Island of New Zealand (Tokoroa, $\left.38^{\circ} 15^{\prime} 36.74^{\prime \prime} S 176^{\circ} 00^{\prime} 35.21^{\prime \prime} \mathrm{E}\right)$. First instar caterpillars of Helicoverpa armigera were obtained from Plant \& Food Research, Auckland. Thirty-five pine seedlings were grown and monitored for the presence of Beauveria endophytes over the course of two years. Trees were cultivated in a glasshouse for the entire duration of the study and grown in 12-14 months old potting mix comprised of $80 \%$ composted bark, $20 \%$ pumice grade 1-7 $\mathrm{mm}, 5 \mathrm{~g} / \mathrm{l}$ osmocote extract, $1 \mathrm{~g} / \mathrm{l}$ horticultural lime and $1 \mathrm{~g} / \mathrm{l}$ hydraflo wetting agent. The potting mixes were also screened for the presence of B. bassiana prior to use by plating on BSM.

Detection of endophyte in two year old P. radiata trees

To determine the presence of Beauveria sp. endophytes, small sections of young roots and one needle fascicle were randomly sampled from 
each pine tree, rinsed under cold water and stored individually at $4^{\circ} \mathrm{C}$. From these samples, a $5 \mathrm{~cm}$ long fragment of one root and one entire needle from the fascicle were surface sterilised ( $5 \mathrm{~min}$ in $2.5 \%$ sodium hypochlorite, rinsed in $\mathrm{sdH}_{2} \mathrm{O}$, then $1 \mathrm{~min}$ in $70 \%$ ethanol and washed $\mathrm{x} 3$ in $\mathrm{sdH}_{2} \mathrm{O}$ ). Root and needle samples were snap frozen and ground in a sterile mortar. DNA extractions were then performed as described. DNA extracts were used in PCR to ascertain which trees were positive for endophytic Beauveria.

Effect of endophytes on below-ground insects

Costelytra zealandica larvae $(\mathrm{n}=96)$ were weighed on a $0.01 \mathrm{~g}$ portable digital scale and their initial weight recorded. Subsequently, using a block design by initial larval weight (i.e. block 1: $0.14 \mathrm{~g}$, block 2: $0.15 \mathrm{~g}$, block 3: $0.16 \mathrm{~g}$ and block 4: $0.16 \mathrm{~g}$ ) to minimise the amount of unexplained variation in the subsequent statistical analysis, larvae were allocated to two different feeding treatments and kept in individual cells in multi-well cell culture plates at $15^{\circ} \mathrm{C}$. Half of the larvae were fed ad libitum with chopped roots from pines endophytically infected with $B$. bassiana (i.e. treatment), while the other half were fed with chopped roots from pines with no detectable Beauveria sp. (i.e. control). Fresh roots were added to the cells twice a week over five weeks. As indicators of fitness, larval survival and growth (measured as weight gain) were recorded weekly, as well as the final weight of each larva at the end of the experiment.

Statistical analyses on the effect of the endophytic occurrence of $B$. bassiana in $P$. radiata on larval survival were carried out by Chi square testing. Larval growth was analysed by analysis of variance (ANOVA, complete block design) after exclusion of the larvae that died before the end of the experiment. Statistical tests were conducted with R version 2.12.1 (R Development Core Team 2011) and GenStat ${ }^{\circledast}$ version 14.1 (VSN International, Hemel Hempstead).
Effect of endophytes on above-ground insects Helicoverpa armigera caterpillars $(\mathrm{n}=80)$ were weighed on a $0.0001 \mathrm{~g}$ readability digital scale and their initial weight recorded. A block design by initial weight, to minimise the amount of unexplained variation, was then followed to allocate the caterpillars to two different feeding treatments. Individual caterpillars were kept in $35 \mathrm{ml}$ plastic containers containing a small pine cutting of $30 \mathrm{~mm}$ long placed in $2 \mathrm{ml}$ eppendorf tubes filled with tap water to ensure that the cuttings remain turgid for the duration of the experiment. Containers were maintained in an incubator at 16:8 L:D cycle, at $23^{\circ} \mathrm{C}$ and $55 \%$ humidity. Half of the caterpillars were given cuttings from pines endophytically infected with $B$. bassiana (i.e. treatment), while the other half were fed with cuttings from control pines containing no endophytes (i.e. control). Pine cuttings were replaced twice during the two week experiment. Mortality and growth (weight gain) were recorded after two weeks. Statistical analyses on the effect of the endophytic occurrence of $B$. bassiana in $P$. radiata on caterpillar survival were carried out by Chi square testing. Growth of the caterpillars was analysed by analysis of variance (ANOVA, complete block design). Statistical tests were conducted with $\mathrm{R}$ version 2.12.1 (R Development Core Team 2011) and GenStat ${ }^{\oplus}$ version 14.1 (VSN International, Hemel Hempstead), respectively.

\section{RESULTS}

\section{Electron microscopy}

A single emerged seedling out of twenty was positive for Beauveria and processed for TEM. Ultrathin sectioning showed fungal hyphae (Figure 1) which was only detected in PCR Beauveria-positive seedlings. Two to three hyphal strands were found intercellular in the pine samples (Figure 1). No fungus grew from the germinated seedling sections placed on semi-selective BSM, presumably because the amount of fungus was too low to remain viable after sterilisation. 


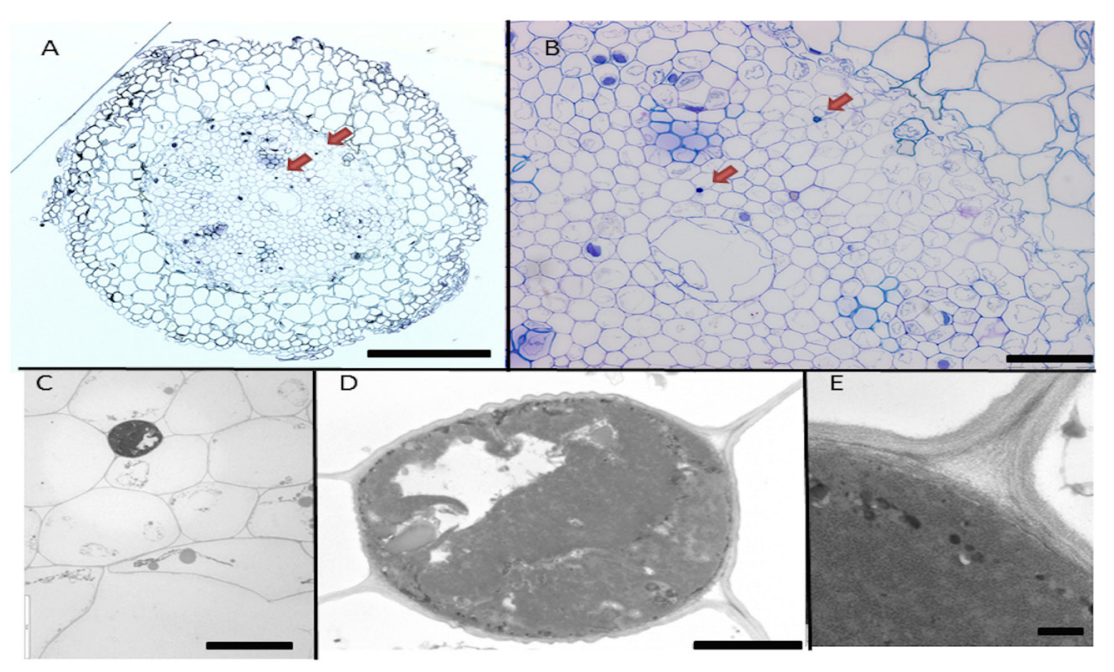

Figure 1 Sections through a Pinus radiata radicle showing putative Beauveria sp. hyphae. A. Thin section stained with toluene blue, with hyphae in intercellular spaces (red arrows) (bar $=200 \mu \mathrm{m})$. B. Close up on thin section (bar $=50 \mu \mathrm{m})$. C, D and E. TEMs of hyphae (bar $=10 \mu \mathrm{m}, 0.2 \mu \mathrm{m}$ and $2 \mu \mathrm{m})$ C. Hypha pushing between plant cells. D. Close up of fungal and plant cell wall interaction. E. Magnified view of $\mathrm{C}$.

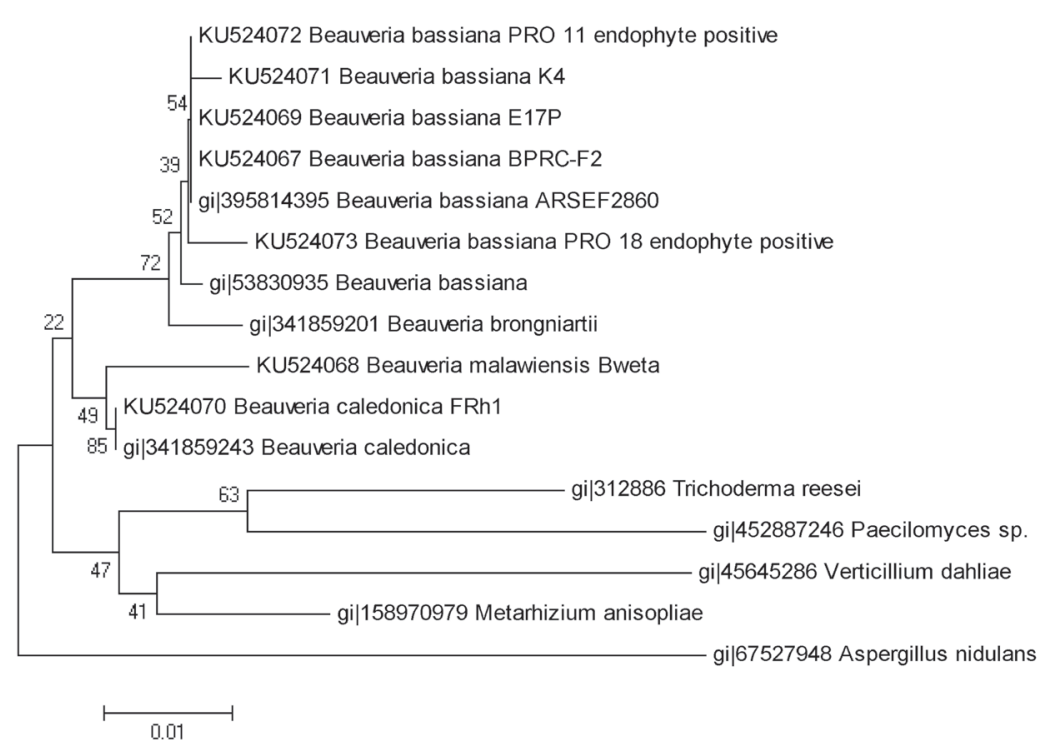

Figure 2 Phylogeny of TEF1- $\alpha$ partial sequences of various Beauveria species (constructed with the Neighbor-Joining method). The endophyte positive $P$. radiata samples are shown here aligning with B. bassiana (PRO 11 and PRO 18). A Beauveria isolate obtained from the same seed-line (BPRC-F2, identical to BPRC-F1) is also shown. Isolates used for comparison are either GenBank obtained or the Lincoln University fungal collection. 2860 =ARSEF 2860 from Genbank ascension ASM28067v1. 
a)

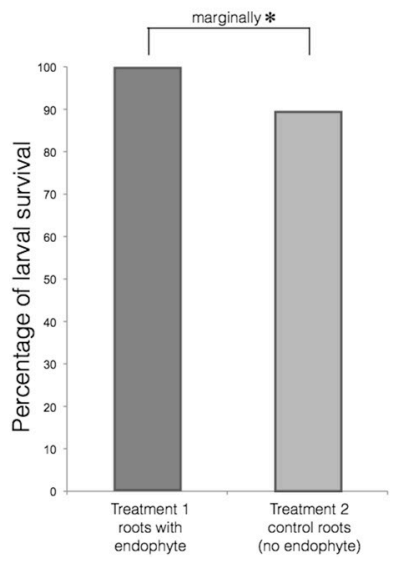

b)

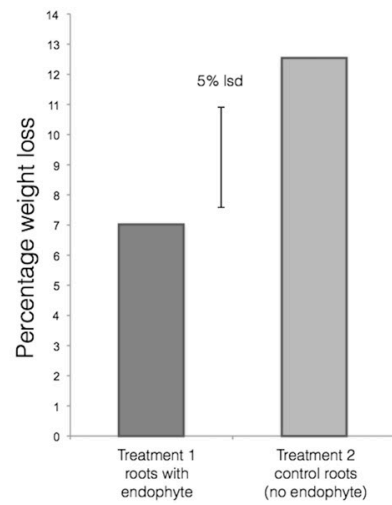

Figure 3 a) Costelytra zealandica larval survival when fed with pine roots free of endophyte and with pine roots endophytically infected with Beauveria bassiana. b) Larval weight variation when fed with pine roots free of endophyte and with pine roots endophytically infected with Beauveria bassiana.

ANOVA (block design) - caterpillar \% weight gain

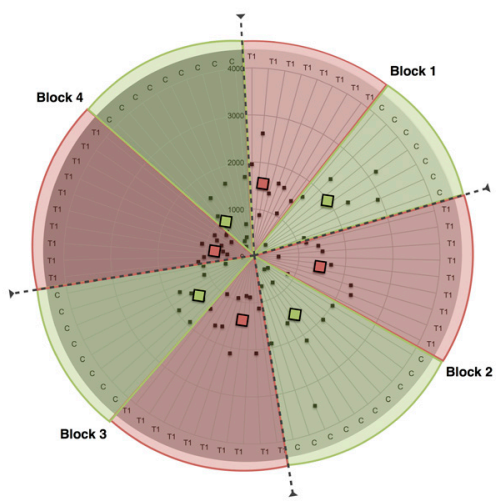

T1 - caterpillars fed with pine needles endophytically infected with $B$. bassiana

C - caterpillars fed with pine needles free of endophyte

Figure 4 Individual Helicoverpa armigera caterpillar percentage weight gain (black dots) and average percentage weight gain per treatment and per block (squares), with the caterpillars fed with pine needles free of endophyte indicated by $(\mathrm{C})$ and the caterpillars fed with pine needles endophytically infected with Beauveria bassiana indicated by (T1).

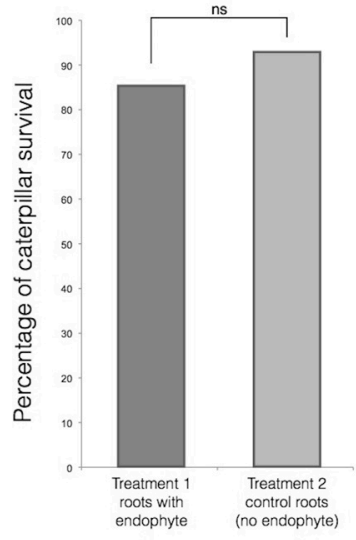

Figure 5 Helicoverpa armigera caterpillar survival of caterpillars fed with pine needles free of endophyte and caterpillars fed with needles endophytically infected with Beauveria bassiana. 


\section{Endophyte detection in $P$. radiata}

From the 30 plants sown and cultured for endophyte isolation, two Beauveria bassiana (sensu stricto clade A, Rehner \& Buckley, 2005) colonies were obtained from the hypocotyl of a single emerged seedlings (isolates designated as BPRC-F1 and BPRC-F2). For the 35 two-year-old pine trees tested, the presence of $B$. bassiana was detected by PCR (confirmed by genotyping) in the roots of two trees (trees PRO 11 and PRO 18, Figure 2). The roots and needles of these two trees were subsequently used as treatment in the two experiments of this study, while the other trees were used as control. The soil in which the trees were grown contained no detectable Beauveria species. For the Maximum Composite Likelihood analysis, the optimal tree with the sum of branch length was 0.2288 (Figure 2). The phylogenetic tree branch lengths indicate evolutionary distances and bootstrapping (Felenstein 1985).

\section{Effect of endophytes on below-ground insects}

Below-ground insect larvae fed with roots free of endophyte survived marginally better than those fed with roots endophytically infected with B. bassiana (at $10 \%$ level of significance) $\left(x^{2}=3.3758\right.$, d.f. $\left.=1, p=0.06616\right)$ (Figure 3a). Although the average weight of the larvae tends to decrease over time under both treatments regardless of their initial weight, it was quite noticeable that the weight of the larvae decreased even more (by almost 5\%) when fed with roots endophytically infected with $B$. bassiana (ANOVA, $\mathrm{F}_{1,86}=10.86, p<0.001$ ) (Figure 3b).

\section{Effect of endophytes on above-ground insects}

Caterpillars fed on pine needles from treatment pines (i.e. endophytically infected with $B$. bassiana) showed neither any impairment in their growth (ANOVA, $\mathrm{F}_{1,66}=1.03, p=0.315$ ) regardless of their initial weight (Figure 4 ) nor survival $\left(\chi^{2}=0.5008\right.$, d.f. $=1, p=0.4792$ ) (Figure 5) compared to the caterpillars fed on pine needles from control pines.

\section{DISCUSSION}

Our study supports that vertical transmission of Beauveria as an endophyte may occur in P. radiata. While there was no PCR detection of Beauveria from ungerminated seed directly, Beauveria was detected in newly emerged seedlings that had no prior exposure to the fungus. Direct observation with TEM of a positive seedling showed the fungus was present in very small quantities, only 2-3 hyphal strands per transverse section. We failed to detect Beauveria in the majority of the young seedlings grown from surface-sterilised seed and from the seed itself using the PCR method. However, based on the observations made from the TEM images it is possible that Beauveria can be present in very small quantities in seed. The seed casing may also contain some inhibitors to the PCR reaction (although seed DNA did amplify with pine specific primers).

Our study also suggests that plant host endophytic infection by Beauveria is relatively rare in nature as B. bassiana was isolated from only two pine seedlings, perhaps indicating vertical transmission. However, a similar genotype of Beauveria was detected two years later from mature plants sown from the same seed batch. This is consistent with a previous study that reported Beauveria was established in pine seedlings from both seeds and roots independently, but only one plant out of thirty was positive for endophytic B. bassiana after 9 months (Brownbridge et al. 2012).

Of the many reports of $B$. bassiana as a plant endophyte, few studies have demonstrated the effect of this fungal association on phytophagous insect pests (e.g. Bing \& Lewis 1991; Cherry et al. 2004; Akello et al. 2008a,b; Quesada-Moraga et al. 2009; Gurulingappa et al. 2010; Akutse et al. 2013). Using C. zealandica and H. armigera as models of below- and above-ground insect feeders respectively, we showed that in $P$. radiata $B$. bassiana significantly reduced the fitness of the below-ground insect feeder, while no effect was observed on the above-ground feeder.

Previously, Griesbach (2000) found that a Fusarium sp. as a plant endophyte resulted in smaller 
larvae of the Banana Weevil Cosmopolites sordidus (Germar) (Coleoptera: Curculionidae) than those feeding on non-inoculated plants. Gurulingappa et al. (2010) found similar effects with the cotton aphid on cotton endophytically infected by $B$. bassiana. This previous research aligns with the weight loss observed in C. zealandica larvae fed with pine infected with $B$. bassiana in the present study.

In a majority of studies, no fungal growth was observed on the dead body of the insects, leading authors to hypothesize that the mode of action of $B$. bassiana might be due to the feeding deterrence induced by fungal metabolites or mycotoxins (Vega, 2008; Mantzoukas et al. 2015) rather than by direct mycosis infection. There is evidence that Beauveria strains produced different mycotoxins, but this has not been reported in planta. This hypothesis is in agreement with our results and would also explain the significant decrease in weight observed in the larvae fed with B. bassiana-infected pines.

It is important to note that the overall loss of weight itself, as observed in the larvae across both feeding treatments, could be due to different factors. Indeed, C. zealandica usually undergo a non-feeding pre-pupation stage (East \& Kain 1981; Wright 1989). This experiment was performed with larvae already weighing between 0.14 and $0.16 \mathrm{~g}$. These larvae might have reached their optimal weight to enter pre-pupation during the course of the experiment, hence ceased feeding at an early stage of the trial, which would have resulted in a similar loss of weight under both feeding treatments. Furthermore, the nutritional value of the host plant on which C. zealandica larvae fed can affect the fitness of the larvae (Lefort et al. 2015; Lefort et al. 2014). It seems that while C. zealandica is able to use $P$. radiata as a host, this plant might not offer all the nutritional qualities required for optimal growth of the insect. Lefort et al. (2014) also suggested the possible occurrence of several races of this species that have become adapted to specific hosts. This might be the reason for pasture-collected insects used in our experiments not gaining weight while feeding on pines.

In our study feeding deterrence appears to be the best explanation of the loss of weight of C. zealandica. Our results also suggest that this effect against insect feeders remains limited to the infected tissue, as we did not detect any deterrent effect on the caterpillars fed with pine needles when only the roots were tested positive for the fungi.

In a study by Akello et al. (2008b), endophytic B. bassiana was isolated from different parts of banana plants, but to a greater extent from the roots and rhizomes of the plant. In the present study, the sampling of the pine needle and the molecular diagnostic for the occurrence of B. bassiana were performed several weeks after the sampling and molecular diagnostic were carried out on the roots. Similarly, the experiments using $H$. armigera caterpillars as the above ground-feeder were performed several weeks after the one on C. zealandica larvae. This raised further questions as to whether the mode of action of B. bassiana occurs through SAR with a limited lifespan or is truly a localised response, depending on the persistence of the endophyte in the plant.

The presence of $B$. bassiana as a vertically transmitted endophyte capable of reducing insect damage could have implication for pest control in these long-lived, commercially-grown trees. The issues around longevity of colonisation would need to be overcome, but it is possible that a vertically transmitted endophyte could provide a persistent and cost-effective solution for protecting commercial $P$. radiata forests from insects.

\section{ACKNOWLEDGEMENTS}

The authors would like to thanks Jenny Brookes, Josefina Narciso, Narges Askari Nejad and Estelle Moreau (Bio-Protection Research Centre, New Zealand) for their technical support and Anne Barrington (Plant \& Food Research Ltd, New Zealand) for providing the caterpillars used in this study. Richard Townsend (AgResearch Ltd, New Zealand) for supplying grass grub larvae. Duane Harland and James Vernon (AgResearch, Lincoln, NZ) provided expert assistance with the transmission electron microscopy. We also thank Prof Leo Condron (Lincoln University) and Dr Stephen Reay (AUT) for advice on the project. 


\section{REFERENCES}

Akello J, Dubois T, Coyne D, Kyamanywa S 2008a. Endophytic Beauveria bassiana in banana (Musa spp.) reduces banana weevil (Cosmopolites sordidus) fitness and damage. Crop Protection 27: 1437-1441.

Akello J, Dubois T, Coyne D, Kyamanywa S 2008b. Effect of endophytic Beauveria bassiana on populations of the banana weevil, Cosmopolites sordidus, and their damage in tissue-cultured banana plants. Entomologia Experimentalis et Applicata 129: 157-165.

Akello J, Sikora R 2012. Systemic acropedal influence of endophyte seed treatment on Acyrthosiphon pisum and Aphis fabae offspring development and reproductive fitness. Biological Control 61: 215-221.

Bing LA, Lewis LC 1991. Suppression of Ostrinia nubilalis (Hubner) (Lepidoptera: Pyralidae) by endophytic Beauveria bassiana (Balsamo) Vuillemin. Environmental Entomology 20: 1207-1211.

Bissett J, Widden P 1988. A new species of Beauveria isolated from Scottish moorland soil, Canadian Journal of Botany 66: 361-362.

Brownbridge M, Reay SD, Nelson TL, Glare TR 2012. Persistence of Beauveria bassiana (Ascomycota: Hypocreales) as an endophyte following inoculation of Radiata pine seed and seedlings. Biological Control 61: 194-200.

Castillo Lopez D, Zhu-Salzman K, Julissa Ek-Ramos M, Sword GA 2014. The entomopathogenic fungal endophytes Purpureocillium lilacinum (formerly Paecilomyces lilacinus) and Beauveria bassiana negatively affect cotton aphid reproduction under both greenhouse and field conditions PLoS One 9.

Chapman RB 1984. Pasture pests. In: New Zealand Pest and Beneficial Insects (ed RR Scott) pp. 119-142. Lincoln University College Press, Lincoln, New Zealand.

Cherry AJ, Banito A, Djegui D, Lomer C 2004. Suppression of the stem-borer Sesamia calamistis (Lepidoptera: Noctuidae) in maize following seed dressing, topical application and stem injection with African isolates of Beauveria bassiana. International. Journal of Pest Management 50: 67e73.

East R, Kain M 1981. Grass grub: biology, damage and control: a summary. Farm Production and Practice 47:1-3.

Felsenstein J 1985. Confidence limits on phylogenies: An approach using the bootstrap. Evolution 39: 783-791.

Ganley RJ, Newcombe G 2006. Fungal endophytes in seeds and needles of Pinus monticola. Mycological Research 110: 318-327.

Gomez-Vidal S, Lopez-Llorca LV, Jansson HB, Salinas J 2006. Endophytic colonization of date palm (Phoenix dactylifera L.) leaves by entomopathogenic fungi. Micron 37: 624632.

Griesbach, M 2000. Occurrence of mutualistic fungal endophytes in bananas (Musa spp.) and their potential as biocontrol agents of banana weevil Cosmopolites sordidus (Germar) in Uganda. Ph.D Thesis, University of Bonn, Bonn, Germany.

Gurulingappa P, Sword GA, Murdoch G, McGee PA 2010. Colonization of crop plants by fungal entomopathogens and their effects on two insect pests when in planta. Biological Control 55: 34-41.

Herman TJB, Davidson MM 2000 Introduction and establishment of Microplitis croceipes, a larval parasitoid of Heliothis, in North Island pine forests. New Zealand Plant Protection 53: 328-333.

Lefort M-C, Boyer S, Vereijsen J, Sprague R, Glare TR, Worner SP 2015. Preference of a native beetle for "exoticism", characteristics that contribute to invasive success of Costelytra zealandica (Scarabaeidae: Melolonthinae). PeerJ 3:e1454.

Lefort M-C, Boyer S, De Romans S, Armstrong K, Glare TR, Worner SP 2014. Invasion success of a scarab beetle within its native range: host-shift vs. host range expansion. PeerJ 2:e262.

Mantzoukas S, Chondrogiannis C, Grammatikopoulos G 2015. Effects of three endophytic entomopathogens on sweet 
sorghum and on the larvae of the stalk borer Sesamia nonagrioides. Entomologia Experimentalis et Applicata 154: 78-87.

McKinnon AC 2011. Rhizosphere colonisation of Beauveria Vuillemin species (Ascomycota: Hypocreales) (B. bassiana and B. caledonica). Masters thesis. Lincoln University, NZ.

Mead DJ. 2013 Sustainable management of Pinus radiata plantations. FAO Forestry Paper No. 170. Rome, FAO.

New Zealand Ministry for Primary Industries 2014 National exotic forest description (as at 1 April 2012). Wellington, Ministry for Primary Industries.

Ownley BH, Griffin MR, Klingeman WE, Gwinn KD, Moulton JK, Pereira RM 2008. Beauveria bassiana: Endophytic colonization and plant disease control. Journal of Invertebrate Pathology 98: 267-270.

Ownley BH, Gwinn KD, Vega FE 2010. Endophytic fungal entomopathogens with activity against plant pathogens: ecology and evolution. Biocontrol 55: 113-128.

Quesada-Moraga E, Munoz-Ledesma FJ, Santiago-Alvarez C 2009. Systemic protection of Papaver somniferum L. against Iraella luteipes (Hymenoptera: Cynipidae) by an endophytic strain of Beauveria bassiana (Ascomycota: Hypocreales). Environmental Entomology 38: 723-730.

Quesada-Moraga E, Lopez-Diaz C, Landa B 2014. The Hidden Habit of the Entomopathogenic Fungus Beauveria bassiana: First Demonstration of Vertical Plant Transmission Plos One, 9.

R Development Core Team 2011 R: A language and environment for statistical computing, version 2.12.1. Vienna, Austria, R Foundation for Statistical Computing. http://www.Rproject.org/.

Reay SD, Brownbridge M, Gicquel B, Cummings NJ, Nelson TL 2010. Isolation and characterization of endophytic Beauveria spp. (Ascomycota: Hypocreales) from Pinus radiata in New Zealand forests. Biological Control 54: 52-60.

Rehner SA, Buckley E 2005. A Beauveria phylogeny inferred from nuclear ITS and EF1-alpha sequences: evidence for cryptic diversification and links to Cordyceps teleomorphs. Mycologia 97: 84-98.

Rehner SA, Minnis AM, Sung G, Luangsa-ard JJ, Devotto L, Humber RA 2011. Phylogeny and systematics of the anamorphic, entomopathogenic genus Beauveria. Mycologia 103: 1055-1073.

Roy HE, Brodie EL, Chandler D, Goettel MS, Pell JK, Wajnberg E, Vega FE 2010. Deep space and hidden depths: understanding the evolution and ecology of fungal entomopathogens. Biocontrol 55: 1-6.

Sang T, Crawford DJ, Stuessy TF 1997. Chloroplast DNA phylogeny, reticulate evolution and biogeography of Paeonia (Paeoniaceae). American Journal of Botany 84: 1120-1136.

Tate JA, Simpson BB 2003. Paraphyly of Tarasa (Malvaceae) and diverse origins of the polyploid species. Systematic Botany 28: 723-737.

Tefera T, Vidal S 2009. Effect of inoculation method and plant growth medium on endophytic colonization of sorghum by the entomopathogenic fungus Beauveria bassiana. Biocontrol 54: 663-669.

Tamura K, Peterson D, Peterson N, Stecher G, Nei M, Kumar S 2011. MEGA5: Molecular Evolutionary Genetics Analysis using Maximum Likelihood, Evolutionary Distance, and Maximum Parsimony Methods. Molecular Biology and Evolution 28:2731-2739

Tamura K, Stecher G, Peterson D, Filipski A, Kumar S 2013. MEGA6: Molecular Evolutionary Genetics Analysis version 6.0. Mol. Biol. and Evol. 30: 2725-2729

Vidal S, Jaber LR 2015. Entomopathogenic fungi as endophytes: plant-endophyteherbivore interactions and prospects for use in biological control. Current Science 109: 46-54.

Wright P 1989. Selection of entomogenous nematodes to control grass grub and porina in pasture. $\mathrm{PhD}$ Thesis, Lincoln University, New Zealand. 